Published online 2017 April 13.

Abstract

\title{
The Normal Value of Tibial Tubercle Trochlear Groove Distance in Patients with Normal Knee Examinations Using MRI
}

\author{
Mohammad Sobhan Ardekani, Reza Nafisi Moghadam, ${ }^{1}$ Mohamadreza Sobhan, Sepehr Nabavinejad, \\ Zoheira Arefmanesh,, ${ }^{2}$ Mani Habibilashgary, and Mahtab Amirheidari \\ ${ }^{1}$ Yazd University of Medical Sciences, Yazd, Iran \\ ${ }^{2}$ Resident \\ "Corresponding author: Zoheira Arefmanesh. E-mail: arefmanesh.md@gmail.com
}

Received 2016 December 21; Accepted 2017 February 08.

\begin{abstract}
Abstract: Patellar instability is a multifactorial common knee pathology that has a high recurrence rate, and the symptoms continue and ultimately predispose the patient to chondromalacia and osteoarthritis. Tibial tuberosity-trochlear groove distance (TTTG) is very important in the assessment of patellofemoral joint instability. The purpose of this study was to report normal value of TTTG in males and females in different age groups and to assess the reliability of MRI in measuring TTTG. All patients presenting with knee pain and normal examinations of knee joint, with a normal MRI report, referring to ShahidSadoughi hospital of Yazd, Iran, from April 2014 to September 2014, were included into the study. MR images were studied once by two radiologists and for the second time by one radiologist. Mean value of TTTG was reported for males and females and in three age groups. Intra- and inter-observer reliability was calculated. A total of 98 patients were eligible to evaluate during 6 months ( 68 male and 30 female). Mean TTTG was $10.9 \pm 2.5 \mathrm{~mm}$ in total, which was $10.8 \pm 2.8 \mathrm{~mm}$ and $11.3 \pm 2.3 \mathrm{~mm}$ in males and females, respectively $(\mathrm{P}>0.05)$. Mean TTTG in males $\leq 30$ years, 30-50 years and, $\geq 51$ years old were $10.8 \pm 2.6 \mathrm{~mm}, 10.8 \pm 2.7 \mathrm{~mm}$, and $10.8 \pm 2.6 \mathrm{~mm}$, respectively; that was $12.1 \pm 3.4 \mathrm{~mm}, 11.4 \pm 1.9 \mathrm{~mm}$, and $10.5 \pm 1.7 \mathrm{~mm}$ in females $\leq 30$ years, 31 - 50 years and, $\geq 51$ years old, respectively (95\% $\mathrm{CI}$ ). The coefficient of variation was $<10 \%$ for both intra- and inter-observer analysis. The results of the present study showed no significant difference in TTTG value between males and females in different age groups. In addition, it demonstrated that MRI is a reliable method in assessment of TTTG and identified normal value for TTTG at $10.9 \pm 2.5 \mathrm{~mm}$.
\end{abstract}

Keywords: Knee, Anatomy, Magnetic Resonance Imaging, TTTG

This is an abstract presented in the 33rd Iranian congress of radiology (ICR) and the 15th congress of Iranian radiographic science association (IRSA)

Copyright (c) 2017, Tehran University of Medical Sciences and Iranian Society of Radiology. This is an open-access article distributed under the terms of the Creative Commons Attribution-NonCommercial 4.0 International License (http://creativecommons.org/licenses/by-nc/4.0/) which permits copy and redistribute the material just in noncommercial usages, provided the original work is properly cited. 